\title{
Does Your Career Affect Your Child's Smile?- Effects of Age and Maternal Employment on Aggression in Adolescents
}

\author{
Dr. Nidhi Gandhi ${ }^{1 *}$
}

\section{ABSTRACT}

The present study examines impact of maternal employment and age on aggression level in adolescents. The sample consists of 100 adolescents of the mothers joining employment in the first year of child's age, 100 adolescents of mother joining employment after the child had turned 5 years or above and 100 adolescents of unemployed mothers. The sample aged between 10-18 years, residing in Ahmedabad city of Gujarat. Aggression scale by R.L. Bharadwaj is used to collect data. Regression Analysis with dummy variables is used for statistical analysis. Results of the study reveal that aggression level in adolescents rises with increase in age thus they are positively correlated. Also maternal employment during the $1^{\text {st }}$ year of child's life shows higher level of aggression in their adolescent age. Later employment of mothers show least level of aggression in their adolescent, even lesser then the adolescents of unemployed mothers. Maternal employment per se does not have effects on aggression level in adolescents.

Keywords: Maternal employment, Aggression, Adolescence

There has been a steady increase in research regarding problems of aggressive behavior among children and adolescents. Human aggression is any behavior directed toward another individual that is carried out with the proximate (immediate) intent to cause harm. In addition, the perpetrator must believe that the behavior will harm the target, and that the target is motivated to avoid the behavior (Bushman \& Anderson 2001, Baron \& Richardson 1994, Berkowitz 1993, Geen 2001).Intention happens to be a very important component in defining Aggression. Aggression might be viewed as a motivational state, a personality characteristic, a response to frustration, an inherent drive or the fulfillment of a socially learned role requirement (Harre and Lamb, 1983).

Aggression have been classified in various ways. Aggression can be a combination of physical or verbal, direct or indirect, passive or active and hostile or instrumental aggression (Buss, 1961).

\footnotetext{
${ }^{1}$ M.A, P.hD (psychology), AGBS Ahmedabad, Amity University, India

*Responding Author

(C) 2016 I N Gandhi; licensee IJIP. This is an Open Access Research distributed under the terms of the Creative Commons Attribution License (http://creativecommons.org/licenses/by/2.0), which permits unrestricted use, distribution, and reproduction in any Medium, provided the original work is properly cited.
} 


\section{Does Your Career Affect Your Child's Smile?- Effects of Age and Maternal Employment on Aggression in Adolescents}

More recent categorization includes hostile, affective or retaliatory aggression versus instrumental, predatory or goal oriented aggression (Behar, Hunt, Ricciuti, Stoff and Vitiello, 1990; Berkowitz, 1993, Bushman and Anderson, 2001).

Aggression is a basic drive common to all species and Human beings, regardless of Sociocultural background, exhibit Aggression in various ways and intensity. Nevertheless other factors play the role of mediators in its development, Aggression seems to be a potential outcome of psychosocio-cultural settings. Frustration, Personality dispositions, culture and climate, socio-economic conditions, age, gender and many more affect aggression (Myers, 1993; Glass, 1997; Neuman and Baron, 1977a).Out of all these etiological factors, age and gender are considerably important in predicting the likelihood of different types of aggressive behavior among children. Studies show that Conflict and physical aggression is common in peer interactions from ages 1-3(Loeber and Hay, 1993;Shantz and shantz, 1985; Tremblay et al, 1996),but it occurs more often to achieve instrumental goals. However for most children the tendency for physical aggression is decreased after age 3 (Tremblay 2000; Tremblay et al., 1996) as they learn to control their aggression as a result of socialization.

Other studies on physical aggression revealed a similar tendency. McGeeet al. (1992) found the prevalence of physical aggression to be higher at age 11 than at age 15.Rahim and Cederblad (1984) found a higher prevalence of physical aggression among3-6-year-old children than among children aged7-15 years. Similarly, Cairns et al. (1989) found that the mean frequency of physically aggressive behaviors was decreasing from 10 to 18 years of age among North Carolina children. However, these studies have important limitations as they relied only on the mean frequency of aggressive behaviors and they compared only two broadly defined age groups. In current study we try to overcome these limitations to some extent.

Moreover although these results are supported by empirical data its generalizations should be made cautiously; as these studies are mostly focused on one particular type of Aggression, that is, physical aggression. Farrington (1993) proposed that aggressiveness can be best measured by different constructs at different ages; for example, fighting at the age of 8, vandalism at age 12 and homicide at age 18. Unfortunately this particular drawback might also be inherent in this study as I have used a single test and an overall score which measures aggression.

However decline in Aggression with Age cannot be generalized. A number of longitudinal studies have reported relationship between physical aggression in childhood and its long-term consequences, such as, violent crimes, alcoholism, drug abuse, partner assault, unemployment and divorce, scholastic difficulties, mental health disorders etc. (Farrington,1994; Fergusson and Horwood, 1998; Huesmannet al., 1984; Kokko and Pulkkinen, 2000; Naginand Tremblay, 1999; Reiss and Roth, 1993; Serbinet al., 1998; Stattin and Magnusson, 1989; Woodward and

(c) The International Journal of Indian Psychology, ISSN 2348-5396 (e)| ISSN: 2349-3429 (p) | 109 


\section{Does Your Career Affect Your Child's Smile?- Effects of Age and Maternal Employment on Aggression in Adolescents}

Fergusson, 2000).It is important to note that these studies focus only on physical aggression whereas, it is not the only way in which aggression is manifested. Others studies highlight that in the preschool and early elementary years, physical aggression generally decreases while verbal aggression increases (Loeber and Hay, 1997; Tremblay, 2000). On the other hand some children increase in aggressiveness as they age. The most dangerous years for Aggressive children are late adolescence and early adulthood. During this period such adolescents are not only more aggressive than earlier but also have greater physical abilities and strength exposure to weapons and other antisocial activities. Thus consequences are more severe (Cairns and Cairns 1994; Verlinden et al., 2000).

Another factor that accounts for discrepancy in magnitude and type of aggression is Gender. Studies have often indicated higher levels of aggression in males. With college students these difference are noticeable right from preschool years with boys showing higher level of physical aggression then girls (Loeber and Hay 1997). Even if small number of girls shows physical aggression at this age, overall they show greater levels of verbal and indirect of aggression (Crick and Grotpeter, 1995; Rys and Bear, 1997). In later elementary grades and adolescence, gender differences increase. On account of this discrepancy gender has been introduced as a controlled variable in our research.

Regarding psychosocial factors that underlie Aggression, research suggests clear link between aggressive behavior in children and adolescent and their family environment. Parenting plays important role in shaping behavior of children and adolescents. However our traditional family system is undergoing major changes these days with increase in the number of women working in recent times. Surveys consistently show increase in number of employed women every year. This change has raised many questions on child development, women empowerment, family wellbeing and social systems and structure in general. There are many controversies that still struggle to find appropriate explanations. Different people have different views about the impact of mothers' job on child development. For many years children of employed women have been compared to unemployed ones with respect to their development and wellbeing. Literature suggests that children of employed mothers differ from homemakers in various aspects. Daughters of working mothers are found to be more aggressive and less passive than daughters of non-working mothers (Miller, 1975). Mody and Murthy (1988) have revealed that the children of employed mothers were found to be careless and slightly emotionally unstable in the early years compared to the children of un-employed mothers.

The opponents argue that attachment between mother and child takes place in the beginning years of children. The most important period of child development is first few years of children and at this stage children need the mothers most. Initially, concerns about maternal employment were to a large extent based on attachment security theory (Bowlby, J. 1969). There is clear and

(C) The International Journal of Indian Psychology, ISSN 2348-5396 (e)| ISSN: 2349-3429 (p) | 110 


\section{Does Your Career Affect Your Child's Smile?- Effects of Age and Maternal Employment on Aggression in Adolescents}

significant association between early infant-mother attachment security and subsequent competence; in all aspects, for instance adjustment and interation with peers (LaFreniere and Sroufe, 1985),activity and independence when exploring new environment (Hazen and Durrett, 1982). Moreover it has also been shown that positive outcomes last beyond early childhood (e.g. Bradley et.al. 1988).

However research has failed to show that a positive attachment is necessarily hampered by maternal employment. Instead, analyses show some mixed reviews on the same. Other controversial issues related to maternal employment concerns the timing at which mother starts working and its effects on her children, particularly during the first year of the child's life. Zsuzsa Blaskó (2008) conducted a review of literature on maternal employment in the first 4 years of child and concluded that early maternal employment by itself has an adverse effect on children's socioemotional development, but this stands true, only if it happens in the first year of child's life. Consequences of later employment, that is, after the child turns 4 years old or above might even might also turn out to be positive. Likewise employed mothers indicate a higher level of well-being than unemployed women which may affect their parenting in positive ways. While the quality and stability of non-maternal care for infants and young children is important, the mother's employment itself does not seem to have the negative effects often proclaimed (Hoffman L. W, 1999). Similarly Hangaland Aminabhavi (2007) discovered that the adolescent children of employed mothers have high emotional maturity, especially female children, and are highly achievement oriented. Also it is observed that maternal employment is associated with higher achievement and fewer internalizing behaviors and employment during Years 2 and 3 is associated with higher achievement (Lucas, Thompson and Goldberg, 2010).

\section{Objectives}

1) To study the impact of age on aggression level of adolescent children.

2) To investigate the impact of maternal employment on aggression level of their adolescent children

\section{METHOD}

\section{Sample}

For this study, a sample of 300 adolescents (children between ages 10 - 18 years) were randomly selected form 4 schools of Ahmedabad, Gujarat i) Ahmedabad International school ii) Calorx public school iii) DAV international school iv)C.N Sheth Vidhyalaya. These students

\section{Tools}

Along with the biographical data sheet, to measure the aggression level among adolescents, Aggression scale developed by Dr. R.L. Bharadwaj is used. The scale focuses on wide variety of behaviors that might be initiated by aggression. It is a self-administered scale including 28 items 


\section{Does Your Career Affect Your Child's Smile?- Effects of Age and Maternal Employment on Aggression in Adolescents}

with five alternatives for each. The test-retest reliability coefficient of the scale is .79, theoretical validity is .83 and construct validity with frustration scale is .78

\section{Procedure}

Firstly the researcher randomly selected schools from Ahmedabad city. Then the students were asked to fill biographical data sheet. Based on their demographics the researcher randomly selected 300 students. Out of these, 100 students had their mothers employed right from the first year of their child's birth, 100 joined work after their child turned 5 years old or later and other 100 were unemployed at all the times. To control the effect of gender on aggression, the sample was equally divided into 150 boys and girls each. The Aggression scale was then administered individually on each respondent.

\section{Statistical analysis}

This paper uses 3 basic regression models with dummy variables to clarify the relationship between employed mothers, unemployed mothers, later employed mothers and aggression level of a child. Here, Age is also included as an independent variable into the models.

$\mathrm{AG}_{1 \mathrm{i}}=-4.32+3.32 \mathrm{D}_{1 \mathrm{i}}+4.73 \mathrm{AGE}_{\mathrm{i}}+\mathrm{u}_{1}$

$\mathrm{AG}_{1 \mathrm{i}}=$ Aggression level of a child

$\mathrm{D}_{1 \mathrm{i}}=1$ if the mother is employed

$=0$ if the mother is unemployed

AGE $=$ Age of a child

$\mathrm{u}_{1 \mathrm{i}}=$ Error

$\mathrm{AG}_{2 \mathrm{i}}=-2.03+6.34 \mathrm{D}_{2 \mathrm{i}}+4.36 \mathrm{AGE}_{\mathrm{i}}$

$\mathrm{AG}_{2 \mathrm{i}}=$ Aggression level of a child

$\mathrm{D}_{2 \mathrm{i}}=1$ if the mother is employed

$=0$ if the mother is later employed

AGE $=$ Age of a child

$\mathrm{u}_{2 \mathrm{i}}=$ Error

$\mathrm{AG}_{3 \mathrm{i}}=-7.87+3.09 \mathrm{D}_{3 \mathrm{i}}+4.76 \mathrm{AGE}_{\mathrm{i}}+\mathrm{u}_{3 \mathrm{i}}$

$\mathrm{AG}_{3 \mathrm{i}}=$ Aggression level of a child

$D_{3 i}=1$ if the mother is later employed

$=0$ if the mother is unemployed

AGE $=$ Age of a child

$\mathrm{u}_{3 \mathrm{i}}=$ Error 
Does Your Career Affect Your Child's Smile?- Effects of Age and Maternal Employment on Aggression in Adolescents

\section{RESULTS AND DISCUSSION}

\section{Table 1: Basic Regression Result with Dummy Variable}

\begin{tabular}{|c|c|c|c|c|c|}
\hline \multicolumn{2}{|l|}{ Model } & \multirow{2}{*}{\begin{tabular}{|l} 
Age \\
4.73
\end{tabular}} & \multirow{2}{*}{\begin{tabular}{|r|} 
Dummy \\
3.32
\end{tabular}} & \multirow{4}{*}{$\begin{array}{l}\text { R-Squared } \\
0.275\end{array}$} & \multirow{4}{*}{$\begin{array}{l}\begin{array}{c}\text { Adjusted } \\
\text { Squared }\end{array} \\
0.268\end{array}$} \\
\hline \multirow{3}{*}{ Model 1} & Coefficient & & & & \\
\hline & t-statistics & 8.59 & 1.21 & & \\
\hline & & $*$ & & & \\
\hline \multirow{3}{*}{ Model 2} & Coefficient & 4.36 & 6.35 & \multirow{3}{*}{0.239} & \multirow{3}{*}{0.231} \\
\hline & t-statistics & 7.64 & 2.14 & & \\
\hline & & $*$ & $* *$ & & \\
\hline \multirow{3}{*}{ Model 3} & Coefficient & 4.76 & 3.09 & \multirow{3}{*}{0.278} & \multirow{3}{*}{0.271} \\
\hline & t-statistics & 8.65 & 1.08 & & \\
\hline & & $*$ & & & \\
\hline
\end{tabular}

(Source: Author's calculation)

$*=1 \%$ significance level; $* *=5 \%$ significance level

Table no. 2 Mean score for Aggression of adolescent children

\begin{tabular}{|c|c|c|c|}
\hline & Employed mothers & $\begin{array}{c}\text { Later employed } \\
\text { mothers }\end{array}$ & $\begin{array}{l}\text { Unemployed } \\
\text { mothers }\end{array}$ \\
\hline Mean (M) & 67.69 & 62.13 & 65.08 \\
\hline $\begin{array}{c}\text { Number of } \\
\text { adolescents (N) }\end{array}$ & 100 & 100 & 100 \\
\hline
\end{tabular}

Table no. 1 shows the results of the 3 different regression models with dummy variables. The table shows Age is most important one into all models and significant at 0.01 level. Age is positively related to Aggression. This suggests that, as child grows over a period of time, aggression level also increases.

Table no. 1 shows there is no statistically significant difference in aggression level of adolescent children of employed and unemployed mothers. (Model no. 1, t-value=1.21). But thus there exist significant difference between aggression levels of adolescent children of mothers employed from the beginning and those of later employed(model no. 2, t-value $=6.35$, $\mathrm{p}<0.05$ ). In case of model 3 , the t-value is 1.08 which is not statistically significant. Table no.2 also shows that the differences in means of the various groups are less pronounced.

\section{CONCLUSION}

This study illustrates that aggression level in adolescents increase with age, for period of adolescence to adulthood. Our results are congruent with the studies that advocate increases in aggression during adolescence. However in the literature we have discussed about various types

(c) The International Journal of Indian Psychology, ISSN 2348-5396 (e)| ISSN: 2349-3429 (p) | 113 


\section{Does Your Career Affect Your Child's Smile?- Effects of Age and Maternal Employment on Aggression in Adolescents}

of aggression in particular, but this study focuses on an overall single score of aggression. So it cannot be clarified what type of aggression adolescent children engage in the most. Thus, to some extent, we are unable to provide justice to the question raised through literature review.

Children of mothers commencing employment soon after the birth have highest level of aggression in their adolescence. Whereas adolescents of later employed mothers have lowest level of aggression, even lower than those of unemployed mothers. Such results indicate that maternal employment per se might not be the cause of aggression in children. Rather the particular stage at which mother joins employment can be the significant factor causing aggression in their adolescents. Thus this study confirms that maternal employment during initial years of the child results in lasting undesirable outcomes, but the same might have reverse outcomes if mother joins employment after the child is 5 years old or above. This difference may exist due to the fact that children sometimes learn to manage themselves on their own when the mother is not always available around. Such children are more independent and emotionally mature. They start exploring their surroundings at earlier age than children of nonworking parents and there are several positive effects of the same.

It is also revealed from the results that discrepancy in all the three groups is less pronounced, in spite of statistically significant difference. This may be attributed to the fact that quality maternal care in absence of mother is usually higher in our country. We live in a collectivistic culture, system of joint family is very common over here, and it is usually observed that the child is attended by other family members in absence of mother due to which effects of maternal employment may be subsidized. Nevertheless this is just an assumption and further clarification requires research in this subject.

Another important consideration is that relationship between maternal employment and child development is mediated by various other factors like mother's experiences in work and characteristics of her employment, such as working time, working conditions, occupational stress, work complexity and other intervening factors like social standing of the family and quality of maternal care provided by substitute in absence of mother all act together to alter this relationship. As this study does not include these various parameters generalization of the findings can be limited.

\section{Acknowledgments}

The author appreciates all those who participated in the study and helped to facilitate the research process.

\section{Conflict of Interests}

The author declared no conflict of interests. 


\section{REFERENCES}

Anderson, C. A., \& Bushman, B. J. (2002). Human aggression. Annual review of Psychology, Volume 53(1), 27-51. DOI: 10.1146/annurev.psych.53.100901.135231

Anderson, C. A., \& Huesmann, L. R. (2003). Human aggression: A social-cognitive view. Handbook of social psychology, 296-323.

Bandura, A. ( 1973). Aggression: A social learning analysis. Prentice-Hall. Oxford, England: Prentice-Hall.

Baron RA, Richardson DR. 1994. Human Aggression. New York: Plenum. 2nd ed.

Behar, D; Hunt, j.; Ricciutic, A.; Stoff,D. \& Vitiello, B. (1990) Subtyping aggression in childeren and adolescents. The Journal of neuropsychiatry and clinical neurosciences, 2, 189-192.

Berkovitz, L. (1993) Aggression: Its Causes, Consequences and Control. New York McGrawHill.

Björkqvist, K. (1994). Sex differences in physical, verbal, and indirect aggression: A review of recent research. Sex roles, 30(3-4), 177-188.

Blasko, Z. (2008). Does early maternal employment affect non-cognitive children outcomes?-A literature review (No. BWP-2008/5). Budapest Working Papers on the Labour Market.

Buss. A.H (1961). The psychology of Aggression. New York: John Wiley\& Sons.

Bushman, B.J \& Anderson, C.A. (2001)it is time to pull the plug on hostile V/s instrumental aggression dichotomy? Psychological Review, 108, 273-279

Cairns, R. B., Cairns, B. D., Neckerman, H. J., Ferguson, L. L., \& Gariépy, J.-L.(1989) ( Vol 25(2), Mar 1989,). Growth and aggression: I. Childhood to early adolescence. Developmental Psychology, 320-330.

Cairns, R. B. (1994). Lifelines and risks: Pathways of youth in our time. New York. Cambridge University Press.

Crick, N. R., \& Grotpeter, J. K. (1995). Relational aggression, gender, and social-psychological adjustment. Child development, 710-722.

Farrington, D. P. (1993). Motivations for conduct disorder and delinquency.Development and Psychopathology, 5(1-2), 225-241.

Farrington DP. (1994). Childhood, adolescent, and adult features of violent males. In: Huesmann LR (ed): Aggressive Behavior: Current Perspectives. New York: Plenum Press, pp 215240.

Fergusson, D. M., \& Horwood, L. J. (1998). Early conduct problems and later life opportunities. Journal of child psychology and psychiatry, 39(08), 1097-1108.

Glass D.C. (1977) Behavior patterns, stres, Stress, Coronary Disease. Hillsdale, N.J. : Erlbaum.

Gujarati, Damodar N.: Basic Econometrics, $4^{\text {th }}$ ed., McGraw-Hill, New York, 2005

Harre, R., \& Lamb, R. (1983). The encyclopedic dictionary of psychology. England: Blackwell. References. 
Hangal S and Aminbhavi A.V (2007). Self- Concept, Emotional Maturity and Achievement Motivation of the Adolescent Children of Employed Mothers and Homemakers. Journal of the Indian Academy of Applied Psychology, Vol. 33 (1), pp 103-110.

Hazen, N. L., \&Durrett, M. E. (1982). Relationship of security of attachment to exploration and cognitive mapping abilities in 2-year-olds. Developmental psychology, 18(5), 751.

Hill, J. L., Waldfogel, J., Brooks-Gunn, J., \& Han, W. J. (2005). Maternal employment and child development: a fresh look using newer methods. Developmental psychology, 41(6), 833.

Hoffman, L. N. W., \& Nye, F. I. (1963). The employed mother in America. Rand McNally.

Hoffman, Lois W. (1974). Effects of maternal employment on the child: A review of the research. Developmental Psychology, Vol 10(2). pp 204-228.

Hoffman, L. N. W., \&Youngblade, L. (1999). Mothers at work: Effects on children's well-being. Cambridge University Press.

Huesmann, L. R., Eron, L. D., Lefkowitz, M. M., \&Walder, L. O. (1984). Stability of aggression over time and generations. Developmental psychology, 20(6), 1120.

Kokko, K., \&Pulkkinen, L. (2000). Aggression in childhood and long-term unemployment in adulthood: a cycle of maladaptation and some protective factors. Developmental psychology, 36(4), 463.

LaFreniere, P. J., \& Sroufe, L. A. (1985). Profiles of peer competence in the preschool: Interrelations between measures, influence of social ecology, and relation to attachment history. Developmental Psychology, 21(1), 56.

Lee, K. H., Baillargeon, R. H., Vermunt, J. K., Wu, H. X., \& Tremblay, R. E. (2007). Age differences in the prevalence of physical aggression among 5-11-year-old Canadian boys and girls. Aggressive Behavior, 33(1), 26-37.DOI: 10.1002/ab.20164

Loeber, R., \& Hay, D.F. (1993). 'Developmental approaches to Aggression and Conduct Problems', in M Rutter and D. F Hay (eds) Development through Life: A Handbook for Clinicians. Oxford Blackwell Scientific. pp 488-516

Loeber, R., \& Hay, D. (1997).Key issues in the development of aggression and violence from childhood to early adulthood. Annual review of psychology, 48(1), 371-410.

Lucas-Thompson, R. G., Goldberg, W. A., \& Prause, J. (2010). Maternal work early in the lives of children and its distal associations with achievement and behavior problems: a metaanalysis. Psychological bulletin, 136(6), 915.DOI: 10.1037/a0020875

McGee, R., Feehan, M., Williams, S., \& Anderson, J. (1992). DSM-III disorders from age 11 to age 15 years. Journal of the American Academy of Child \& Adolescent Psychiatry, 31(1), 50-59.doi:10.1097/00004583-199201000-00009

Miller, S. M. (1975). Effects of maternal employment on sex role perception, interests, and selfesteem in kindergarten girls. Developmental Psychology, Vol. 11(3), 405.

Mody, S. N., \& Murthy, V. N. (1988). The study of mental health of children of working mothers. Journal of personality and clinical studies.

Myers, D.G (1993) Social Psychology. New York :McGraw-Hill. INC 
Nagin, D., \& Tremblay, R. E. (1999). Trajectories of boys' physical aggression, opposition, and hyperactivity on the path to physically violent and nonviolent juvenile delinquency. Child development, 70(5), 1181-1196.

Neuman, J.H. \& Baron, R.A. (1977a) Aggression in workplace. In R. Giacalone and J. Greenbergs (Eds.) Antisocial Behavior in Organizations. Thousand Oaks. C.A. : Sage.

Rahim, S. I. A., \& Cederblad, M. (1986). Effects of rapid urbanization on child behaviour and health in a part of Khartoum, Sudan-II. Psycho-social influences on behaviour. Social Science \& Medicine, 22(7), 723-730.

Ramirez, J. M. (2003). Hormones and aggression in childhood and adolescence. Aggression and violent behavior, 8(6), 621-644.

Roth, J. A., \& Reiss Jr, A. J. (Eds.). (1993). Understanding and preventing violence (Vol. 1). National Academies Press.

Rys, G. S., \& Bear, G. G. (1997). Relational aggression and peer relations: Gender and developmental issues. Merrill-Palmer Quarterly (1982-), 87-106.

Serbin, L. A., Cooperman, J. M., Peters, P. L., Lehoux, P. M., Stack, D. M., \& Schwartzman, A. E. (1998). Intergenerational transfer of psychosocial risk in women with childhood histories of aggression, withdrawal, or aggression and withdrawal. Developmental psychology, 34(6), 1246.

Shantz, C. U., \&Shantz, D. W. (1985). Conflict between children: Social-cognitive and sociometric correlates. New Directions for Child and Adolescent Development, 1985(29), $3-21$.

Skiba, R. J. (2000). Zero tolerance. Zero evidence. An analysis of school disciplinary practice. Indiana: Policy Research Report.

Smith, P. K. (Ed.). (2003). Violence in schools: The response in Europe. London: Routledge Falmer.

Stattin, H., \& Magnusson, D. (1989). The role of early aggressive behavior in the frequency, seriousness, and types of later crime. Journal of Consulting and Clinical Psychology, 57(6), 710.

Tremblay, R. E. (2000). The development of aggressive behaviour during childhood: What have we learned in the past century?. International Journal of Behavioral Development, 24(2), 129-141.

Tremblay, R. E., Boulerice, B., Harden, P. W., McDuff, P., Pérusse, D., Pihl, R. O., \& Zoccolillo, M. (1996). Do children in Canada become more aggressive as they approach adolescence. Human Resources Development Canada \& Statistics Canada (Eds.), Growing up in Canada: National Longitudinal Survey of Children and Youth, 127-137.

Tremblay, R. E., Japel, C., Perusse, D., McDuff, P., Boivin, M., Zoccolillo, M., \& Montplaisir, J. (1999). The search for the age of 'onset'of physical aggression: Rousseau and Bandura revisited. Criminal Behaviour and Mental Health, 9(1), 8-23. 
Does Your Career Affect Your Child's Smile?- Effects of Age and Maternal Employment on Aggression in Adolescents

Verlinden, S., Hersen, M., \& Thomas, J. (2000). Risk factors in school shootings. Clinical psychology review, 20(1), 3-56.

Woodward, L. J., \& Fergusson, D. M. (2000). Childhood And Adolescent Predictors Of Physical Assault: A Prospective Longitudinal Study*. Criminology, 38(1), 233-262.

Youngblade, L. M. (2003). Peer and teacher ratings of third-and fourth-grade children's social behavior as a function of early maternal employment. Journal of child psychology and psychiatry, 44(4), 477-488.

How to cite this article: N Gandhi (2016), Does Your Career Affect Your Child's Smile?Effects of Age and Maternal Employment on Aggression in Adolescents, International Journal of Indian Psychology, Volume 3, Issue 4, No. 58, ISSN 2348-5396 (e), ISSN: 2349-3429 (p), DIP: 18.01.052/20160304, ISBN: 978-1-365-24976-1

(c) The International Journal of Indian Psychology, ISSN 2348-5396 (e)| ISSN: 2349-3429 (p) | 118 